\title{
On Grammar Functions of Tone Modification in Liangshan Yi Language
}

\author{
Sha-ma Dage * Xiao Xue **
}

\begin{abstract}
There is a special grammar phenomena in Liangshan Yi such that grammartical relations can be changed through tone change. When personal pronouns combine with verbs, from the view of personal pronouns, the sentences are in SV pattern if personal pronouns are mid-level tones, while the sentences are in OV pattern when personal pronouns are sub-high tones. From the view of verbs, the sentences are in SV pattern if verbs are low-falling tones while the sentences are in OV pattern when verbs are sub-high tones. This paper discusses how case relations can be marked with grammatical tone in the Yi language.
\end{abstract}

Key words: Liangshan Yi, tone change, personal pronoun, verb, grammartical relation

\section{Introduction}

In the Yi language, tone normally functions to distinguish the meanings of words; that is, tone is lexical. Grammatical relations in Yi are primarily expressed through word order and the use of function words. Thus it is noteworthy that changes in grammatical relations can be marked by modifications in the tones of pronouns and of the verbs associated with them in a sentence.

\section{The role of verbs in grammatical changes wrought by tone modification}

When personal pronouns combine with verbs in $\mathrm{Yi}$, there are some restrictions on the ways in which the verbs may change the grammatical relationship through tone modification. Not all verbs may participate in these modifications in the same way.

1.1. Transitive, but not intransitive, verbs may change their tone to express a different relationship with an associated pronoun.

\footnotetext{
${ }^{*}$ Sha-ma Dage: Yi-language department of Xichang College, Sichuan, 615022, China. E-mail: smdg01@ 126.com.

** Xiao Xue: Yi-language department of Xichang College, Sichuan, 615022, China. E-mail: xuecai2004@ 163.com.
} 
When pronoun precedes a transitive verb, the two normally bear a SV relationship. However, when the verb's tone is changed, the relationship can become an OV relationship. For example:

$$
\begin{aligned}
& \text { 【 } \mathrm{sud}^{21} \rightarrow \mathrm{sud}^{34} 】 \quad \mathrm{ya}^{33} \mathrm{sud}^{21} \quad \text { (I find) } \quad \mathrm{ja}^{33} \mathrm{su}^{34} \quad \text { (to find me) } \\
& 【 \mathrm{yo}^{21} \rightarrow \mathrm{no}^{34} 】 \quad \operatorname{tsh}^{33} \mathrm{po}^{21} \quad \text { (He misses) } \operatorname{tsh}^{33} \mathrm{po}^{34} \quad \text { (to miss him) } \\
& \text { 【hw }{ }^{21} \rightarrow \mathrm{hu}^{34} 】 \quad \mathrm{nu}^{33} \mathrm{hu}^{21} \quad \text { (You see) } \quad \mathrm{nu}^{33} \mathrm{hur}^{34} \quad \text { (to see you) }
\end{aligned}
$$

There is a restriction on polysyllabic verbs. The change from an SV to OV relationship can be accomplished through a tone change in monosyllabic verbs, but not in polysyllabic words. Where the verb is polysyllabic, this change in grammatical relationship must be marked by changing the tone of the pronoun. For example:

$$
\begin{aligned}
& \mathrm{ya}^{33} \mathrm{Su}^{21} \mathrm{ngo}^{55} \mathrm{ndzo}^{33} \quad \text { (I am researching) } \quad \mathrm{ya}^{34} \mathrm{su}^{21} \mathrm{ngo}^{55} \mathrm{ndzo}^{33} \quad \text { (Be researching for me) } \\
& \operatorname{tsh}_{1}{ }^{33} \mathrm{z}^{21} \mathrm{tchi}^{34} \mathrm{ku}^{33} \quad \text { (he is cursing) } \quad \operatorname{tsh}^{34} \mathrm{zl}^{21} \mathrm{tchi}^{34} \mathrm{kur}^{33} \quad \text { (Be cursing him) } \\
& \mathrm{nu}^{33} \mathrm{hu}^{21} \mathrm{fu}^{55} \mathrm{ku}^{33} \quad \text { (You are observing) } \quad \mathrm{nu}^{34} \mathrm{hu}^{21} \mathrm{hu}^{55} \mathrm{ku}^{33} \quad \text { (Be observing you) } \\
& \mathrm{na}^{33} \mathrm{he}^{33} \mathrm{vu}^{33} \quad \text { (I like) } \quad \mathrm{na}^{34} \mathrm{he}^{33} \mathrm{vu}^{33} \quad \text { (To like me) } \\
& \mathrm{nu}^{33} \mathrm{ho}^{33} \mathrm{lo}^{33} \quad \text { (You wish) } \quad \mathrm{nu}^{34} \mathrm{ho}^{33} \mathrm{lo}^{33} \quad \text { (To wish you) }
\end{aligned}
$$

From these examples given above, we find that personal pronouns can also convert the grammar relationship from SV to $\mathrm{OV}$ by their tone modification, such as $\mathrm{ya}^{33} \rightarrow$ $\mathrm{ya}^{34}, \mathrm{tsh}^{33} \rightarrow \mathrm{tsh}^{34}, \mathrm{nu}^{33} \rightarrow \mathrm{nu}^{34}$, when polysyllabic verbs, such as $\mathrm{su}^{21} \mathrm{ngo}^{55}$, $\mathrm{zl}^{21} \mathrm{tchi}^{34}, \mathrm{hu}^{21} \mathrm{lu}^{55}, \mathrm{he}^{33} \mathrm{vu}^{33}, \mathrm{ho}^{33} \mathrm{lo}^{33}$, cannot change their tones to convert their grammar relationship. Tone change in pronouns will be further discussed below, in section 2.

\subsection{Monosyllabic verbs with low-falling tone can change grammatical relationships by converting to sub-high tone}

When a monosyllabic verb in Yi language converts its tone from low-falling tone to sub-high tone, its grammatical relationship with its associated pronoun in a sentence changes from SV to OV. For example:

$\begin{array}{llll}\mathrm{nu}^{33} \mathrm{bl}^{21} & \text { (You give) } & \mathrm{nu}^{33} \mathrm{bl}^{34} & \text { (To give you) } \\ \mathrm{tsh}^{33} \mathrm{ndu}^{21} & \text { (He hits) } & \mathrm{tsh}^{33} \mathrm{ndu}^{34} & \text { (To hit him) } \\ \mathrm{na}^{33} \mathrm{si}^{21} & \text { (I support) } & \mathrm{na}^{33} \mathrm{si}^{34} & \text { (To support me) } \\ \mathrm{na}^{33} \mathrm{~s}^{21} & \text { (I recognize) } & \mathrm{na}^{33} \mathrm{~s}^{34} & \text { (To recognize me) } \\ \mathrm{nu}^{33} \mathrm{pl}^{21} & \text { (You carry) } & \mathrm{nu}^{33} \mathrm{pl}^{34} & \text { (To carry you) } \\ \mathrm{nu}^{33} \mathrm{di}^{21} & \text { (You push) } & \mathrm{nu}^{33} \mathrm{di}^{34} & \text { (To push you) } \\ \operatorname{tsh}^{33} \mathrm{Sq}^{21} & \text { (He sends off) } & \mathrm{tsh}^{33} \mathrm{sl}^{34} & \text { (To send him off) } \\ \operatorname{tsh}^{33} \mathrm{vu}^{21} & \text { (He sells) } & \mathrm{tsh}^{33} \mathrm{vu}^{34} & \text { (To sell him) }\end{array}$




$$
\mathrm{ya}^{33} \mathrm{hi}^{21} \quad \text { (I talk) } \quad \mathrm{ya}^{33} \mathrm{hi}^{34} \quad \text { (To talk about me) }
$$

In these examples mentioned above, the grammatical relationships of these sentences change from $\mathrm{SV}$ to $\mathrm{OV}$ after monosyllabic verbs convert their tone, such as $\mathrm{b}^{21} \rightarrow$ $\mathrm{b}_{1}^{34}, \mathrm{ndu}^{21} \rightarrow \mathrm{ndu}^{34}, \mathrm{si}^{21} \rightarrow \mathrm{si}^{34}, \mathrm{sl}^{21} \rightarrow \mathrm{sl}^{34}, \mathrm{pl}^{21} \rightarrow \mathrm{pl}^{34}, \mathrm{di}^{21} \rightarrow \mathrm{di}^{34}, \mathrm{sl}^{21} \rightarrow \mathrm{Sl}^{34}, \mathrm{vu}^{21} \rightarrow$ $\mathrm{vu}^{34}, \mathrm{hi}^{21} \rightarrow \mathrm{hi}^{34}$.

\subsection{Restriction on mid-level tone verbs}

When mid-level tone verbs combine with personal pronouns, the verb does not change its tone; instead, the associated personal pronoun changes its tone. If a personal pronoun displays mid-level tone, the sentence will be SV. In contrast, if the personal pronoun acquires sub-high tone, the sentence will be OV.

When verbs with high-level tone are linked with personal pronouns, neither verb nor personal pronoun may change their tones. In such cases, the identical sentences can receive either an SV or an OV interpretation. Personal pronouns can either be singular forms or plural forms. Further discussion of tone changes in personal pronouns may be found in section 2 .

$$
\begin{array}{llll}
\mathrm{ya}^{33} \mathrm{tu}^{55} & \text { I trample (or to trample me) } & \mathrm{yo}^{21} \mathrm{yo}^{34} \mathrm{tch}^{55} & \text { We tie (or to tie us) } \\
\mathrm{nu}^{33} \mathrm{Ci}^{55} & \text { You bite (or to bite you) } & \mathrm{no}^{21} \mathrm{yo}^{34} \mathrm{Si}^{55} & \text { You kill (or to kill you) } \\
\text { tsho }^{21} \mathrm{yo}^{34} \mathrm{ma}^{55} & \text { They teach (or to teach them) } & \mathrm{tsh}^{33} \mathrm{bu}^{55} & \text { She kisses (or to kiss her) }
\end{array}
$$

\section{The role of pronouns in grammatical changes wrought by tone modification}

When personal pronouns are bonded with verbs, personal pronouns can change the grammar relationship with some tone modification rules.

\subsection{Restriction on dual and plural forms of personal pronouns}

When personal pronouns combine with verbs in Yi language, only singular pronouns can change the grammatical relationship by modification of their own tone; dual and plural forms, however, cannot. If dual and plural personal pronouns combine with monosyllabic verbs, the change from SV to OV can be accomplished by a change in the tone of the verb from low-falling to sub-high.

$\begin{array}{lccl}\text { Person } & \text { Singular Number } & \text { Dual Number } & \text { Plural Number } \\ \text { The first person } & \mathrm{na}^{33} & \mathrm{na}^{21} \mathrm{ni}^{55} & \mathrm{no}^{21} / \mathrm{no}^{21} \mathrm{yo}^{34} \\ \text { The second person } & \mathrm{nu}^{33} & \mathrm{ni}^{21} \mathrm{ni}^{55} & \mathrm{no}^{21} / \mathrm{no}^{21} \mathrm{yo}^{34} \\ \text { The third person } & \mathrm{tsh}^{33} & \mathrm{tsh}^{21} \mathrm{ni}^{55} & \mathrm{tho}^{21} / \mathrm{thho}^{21} \mathrm{yo}^{34} \\ \text { Alternative name } & \mathrm{su}^{33} & & \end{array}$

Below are three ways, conditioned by the pronoun, to change a clause from SV to OV. 
A. Singular personal pronouns' tone can be changed. For example:

$$
\begin{array}{ll}
\mathrm{ya}^{33}\left(\mathrm{nu}^{33}, \mathrm{tsh}^{33}, \mathrm{su}^{33}\right) \mathrm{gi}^{55} \mathrm{tsh}^{33} & \mathrm{I} \text { (you, he, the others) eliminate/ eliminates } \\
\mathrm{na}^{34}\left(\mathrm{nu}^{34}, \mathrm{tsh}^{34}, \mathrm{su}^{34}\right) \mathrm{gi}^{55} \mathrm{tsh}^{33} & \text { To eliminate me ( you, him, the others) }
\end{array}
$$

After singular personal pronouns convert to sub-high tones, the grammar relationship converts from $\mathrm{SV}$ to $\mathrm{OV}$.

B. When the personal pronoun is dual, the tone of the verb can be changed instead, as long as this verb is monosyllabic. For example:

$$
\begin{array}{ll}
\mathrm{ya}^{21} \mathrm{ni}_{\mathrm{i}} \mathrm{i}^{55}\left(\mathrm{ni}^{21} \mathrm{ni}^{55}, \mathrm{tsh}^{21} \mathrm{ni}^{55}\right) \mathrm{s}^{21} & \text { We ( you, they) know } \\
\mathrm{ya}^{21} \mathrm{n}_{\mathrm{i}} \mathrm{i}^{55}\left(\mathrm{ni}^{21} \mathrm{n}_{\mathrm{i}} \mathrm{i}^{55}, \mathrm{tsh}^{21} \mathrm{ni}_{\mathrm{i}} \mathrm{i}^{55}\right) \mathrm{s}^{34} & \text { To know us (you, them) }
\end{array}
$$

Dual personal pronouns do not change their tone, but if the verb is monosyllabic and of low-falling tone, the grammatical relation can be changed from SV to OV by changing the tone of the monosyllabic from low-falling tone $\mathrm{s}^{21}$ to sub-high tone $\mathrm{s} 1^{34}$.

C. When the personal pronoun is plural, the tone of the verb can be changed instead, as long as this verb is monosyllabic. For example:

$$
\begin{array}{ll}
\mathrm{yo}^{21} \mathrm{yo}^{34}\left(\mathrm{no}^{21} \mathrm{yo}^{34}, \mathrm{tsho}^{21} \mathrm{yo}^{34}\right) \mathrm{di}^{21} & \text { We (you, they) push } \\
\mathrm{yo}^{21} \mathrm{yo}^{34}\left(\mathrm{no}^{21} \mathrm{yo}^{34}, \mathrm{tsho}^{21} \mathrm{yo}^{34}\right) \mathrm{di}^{34} & \text { To push us (you, them) }
\end{array}
$$

Plural personal pronouns do not change their tone when a monosyllabic verb converts its tone form low-falling tone $\mathrm{di}^{21}$ to sub-high tone $\mathrm{di}^{34}$ to change the grammatical relation from SV to OV.

The genitive and accusative forms of personal pronouns cannot change their grammatical relationships by tone modification.

\subsection{Singular personal pronouns with quotation case can change their grammatical relationships by tone modification}

There are very few personal pronouns with quotation case to be found in other languages. They are personal pronouns used in direct quotation to indirectly quote original speakers' words. They only have first personal forms but have number distinction.

Following are the personal pronouns with quotation case in $\mathrm{Yi}: \mathrm{i}^{33}$ (she or he), $\mathrm{i}^{21} \mathrm{ni}^{55}$ (they (two persons)), $\mathrm{o}^{21} / \mathrm{o}^{21} \mathrm{yo}^{34}$ (they (three persons or more)). They can be directly bound with verbs, and their singular forms can change their grammatical relationship by tone modification. If a personal pronoun with quotation case and the associated verb are both mid-level tone, they are SV. But when personal pronouns with quotation case are converted into high-level tones, they are OV. For example:
$\mathrm{i}^{33} \mathrm{to}^{33}$
(He embraces)
$\mathrm{i}^{34} \mathrm{to}^{33}$
(To embrace him)
$\mathrm{i}^{33} \mathrm{Zo}^{33}$
(He learns)
$\mathrm{i}^{34} \mathrm{zo}^{33}$
(To learn from him) 
$\mathrm{i}^{33} \mathrm{ku}^{33} \quad$ (He eats) $\quad \mathrm{i}^{34} \mathrm{ku}^{33} \quad$ (To eat him)

2.3. Personal pronouns with common case can change their grammatical relationships by tone modification

Tone changes in singular pronouns associated with mid-level tone verbs were analyzed above, in section 1 .
$\mathrm{na}^{33} \mathrm{mo}^{33}$
(I see)
$\mathrm{ya}^{34} \mathrm{mo}^{33}$
(To see me)
$\mathrm{nu}^{33} \mathrm{~d} \mathbf{1}^{33}$
(You ride or you meet)
$\mathrm{num}^{34} \mathrm{~d}^{33}$
(To ride you or to meet you)
$\mathrm{tsh}^{33} \mathrm{kha}^{33}$
(He needs)
tsh ${ }^{34} \mathrm{kha}^{33}$
(To need him)
$\mathrm{su}^{33} \mathrm{za}^{33}$
(The others scold)
$\mathrm{su}^{34} \mathrm{za}^{33}$
(To scold the others)

After these personal pronouns convert their tones, such as $\mathrm{ya}^{33} \rightarrow \mathrm{ya}^{34}, \mathrm{nu}^{33} \rightarrow$ $\mathrm{nu}^{34}, \mathrm{tsh}^{33} \rightarrow \mathrm{nu}^{34}, \mathrm{su}^{33} \rightarrow \mathrm{su}^{34}$, their grammatical relationship also changes from SV to OV.

\section{Distinguishing the grammatical relationships between personal pronouns and verbs in Yi}

When personal pronouns are combined with verbs, it is relatively easy to determine the grammatical relationships in sentences in which the tone of the pronoun or verb has been modified. But when the tone has not been changed, it is sometimes true that the grammatical relationship between pronoun and verb could be either SV or OV, and these sentences are difficult to analyze. Below are two situations in which such a phenomenon occurs.

In terms of the characteristics of pronouns, the use of dual or plural personal pronouns with some verbs signifies either an $\mathrm{SV}$ or an $\mathrm{OV}$ relation. For example, " $\mathrm{na}^{21} \mathrm{ndi}^{55}\left(\mathrm{ni}^{21} \mathrm{ni}^{55}\right.$, $\left.\operatorname{tsh}^{21} \mathrm{ni}^{55}, \mathrm{yo}^{21} \mathrm{yo}^{34}, \mathrm{no}^{21} \mathrm{yo}^{34}, \mathrm{tsho}^{21} \mathrm{yo}^{34}\right) \mathrm{hu}^{21}\left(\mathrm{du}^{33}, \mathrm{kha}^{33}\right)$ " means "we/ you/ they see/ eat/ need" or "to see/ eat/ need us/ you/ them".

In terms of the characteristics of verbs, the use of personal pronouns with verbs of high-level tone also signifies either an SV or an OV relation. For example:

$$
\begin{array}{llll}
\mathrm{ya}^{33} \mathrm{tu}^{55} & \text { I trample (or to trample me) } & \mathrm{no}^{21} \mathrm{yo}^{34} \mathrm{tch}^{55} & \text { We tie (or to tie us) } \\
\mathrm{nu}^{33} \mathrm{Ci}^{55} & \text { You bite (or to bite you) } & \mathrm{no}^{21} \mathrm{yo}^{34} \mathrm{si}^{55} & \text { You kill (or to kill you) } \\
\mathrm{tsho}^{21} \mathrm{yo}^{34} \mathrm{ma}^{55} & \text { They teach (or to teach them) } & \mathrm{tsh}^{33} \mathrm{bu}^{55} & \text { She kisses (or to kiss her) }
\end{array}
$$

We cannot determine the grammatical relationship in these two above-mentioned sentence patterns only from their forms. But we can do so by observing the following three points.

A. Agentive and objective 
If the personal pronoun represents an agent, the sentences are SV; if the personal pronoun is a patient, the sentences are OV. For example, " $\mathrm{ya}^{21} \mathrm{ni}^{55}$ ", in the phrases $\mathrm{na}^{21} \mathrm{ni}^{55} \mathrm{hu}^{21}$ (we see), and $\mathrm{ya}^{21} \mathrm{ni}_{\mathrm{i}}{ }^{55} \mathrm{ma}^{55}$ (we teach), can be an agentive, and consequently make the sentence SV. However " $\mathrm{a}^{21} \mathrm{ni}^{55}$ ", if used as an object, can also make the sentence OV.

B. Taking advantage of negative adverbs

We can judge sentences' grammatical relations by inserting negative adverbs with different moods. If the addition of a normal negative adverb $\mathrm{a}^{21}$ (not) results in a fluent sentence, the grammatical relationship will be SV. If instead an imperatively negative adverb tha ${ }^{55}$ (don't) is added, and the resulting sentence is fluent, the grammatical relationship will be OV. For example:

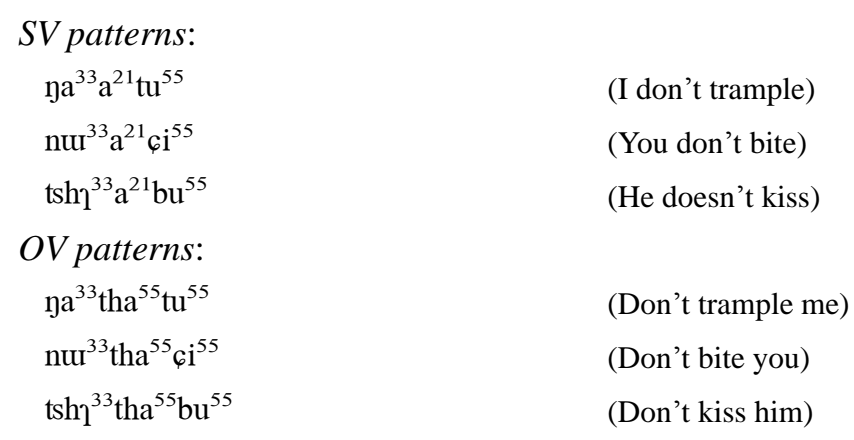

This method of analysis is primarily applicable to situations in which verbs are used with first-person pronouns.

C. Adding objects

If the sentences are not affected on their expressed forms and contents after we add objects, the sentences are SV patterns. For example:
$\mathrm{na}^{21} \mathrm{ni}^{55} \mathrm{hur}^{21}$
(We see)
$\mathrm{ya}^{21} \mathrm{ni}^{55}$ thum $^{21} \mathrm{zl}^{33} \mathrm{hu}^{21}$
(We read books)
$\mathrm{ya}^{33} \mathrm{si}^{55}$
(I slaughter)
$\mathrm{ya}^{33} 1 \mathrm{um}^{33} \mathrm{si}^{55}$
(I slaughtered cattle)
$\mathrm{ya}^{21} \mathrm{ni}^{55} \mathrm{ma}^{55}$
(We teach)
$\mathrm{ya}^{21} \mathrm{ni}^{55} \mathrm{zo}^{34} \mathrm{zu}^{33} \mathrm{ma}^{55}$
(We teach students)

If the sentences are affected on their expressed forms after we add objects, the sentence structure is changed, and personal pronouns become prepositional objects in passive sentences with object fronting, the sentences are OV patterns. For example:
$\mathrm{nu}^{33} \mathrm{ci}^{55}$
(You bite)
$\mathrm{nu}^{33} \mathrm{khur}^{33} \mathrm{ci}^{55}$
(You are bitten by a dog)
$\operatorname{tsh}^{33} \mathrm{si}^{55}$
(He kill)
$\operatorname{tsh}{ }^{33} \mathrm{pa}^{33} \mathrm{si}^{55} \mathrm{pi}^{21} \mathrm{o}^{34}$
(He was hurt by me)

On the basis of the above examples from Liangshan Yi, we can see that, in combinations of personal pronouns and verbs, there are special cases in which tone change changes the 
grammatical sense of a sentence. From the view of personal pronouns, the sentences are SV patterns if personal pronouns are mid-level tones, while the sentences are OV patterns when personal pronouns are sub-high tones. From the view of verbs, the sentences are SV patterns if verbs are low-falling tones while the sentences are OV patterns when verbs are sub-high tones.

\section{References}

Li Ming \& Ma Ming. 1987. Yi Language's Grammar in Liangshan. [M] Chengdu: Sichuan national press.

Qu-mu Tie-xi \& Chen Shi-lin. 1988. Yi Language's Fundamental Knowledge. [M] Chengdu: Sichuan national press.

Shen Yunfeng. 1990. Modern Yi Language in Liangshan. [M] Chengdu: Sichuan national press.

Zhang Yurong, Cai Kun. 1995. Modern Yi Language's Grammar in Liangshan. [M] Beijing: Central university for nationalities press. 